\title{
CARACTERIZAÇÃO DO PERFIL EPIDEMIOLÓGICO DE UMA PANDEMIA EM TERRITÓRIO BRASILEIRO: INFLUENZA A (H1N1)
}

\author{
CHARACTERIZATION OF THE EPIDEMIOLOGICAL PROFILE OF A \\ PANDEMIC IN BRAZILIAN TERRITORY: INFLUENZA A (H1N1)
}

\author{
Alison Pontes da Silva ${ }^{1}$ \\ Diogo Leonardo Santos Silva ${ }^{2}$ \\ Bruna Braga Dantas ${ }^{3}$
}

RESUMO: OBJETIVO: Verificar os dados epidemiológicos sobre a influenza pandêmica no Brasil. METODOLOGIA: Estudo de caráter documental e retrospectivo, com dados do Departamento de Informática do Sistema Único de Saúde (DATASUS), entre 2009 e 2010. As notificações foram coletadas quanto à classificação final e os casos confirmados foram analisados por região geográfica, evolução, sexo, faixa etária, condição de gestação e taxa de letalidade. RESULTADOS: Durante as fases de contenção e mitigação, houveram 97.250 notificações, das quais $55,7 \%$ foram confirmadas e $44,3 \%$ descartadas. O ano de 2009 concentrou o maior número de notificações ( $\mathrm{N}=89.642)$ em comparação com 2010 ( $N=8.664)$. Os dados por região indicaram que as regiões Sul e Sudeste detiveram grande parte dos casos confirmados e óbitos, embora a região CentroOeste tenha obtido a maior letalidade do país. Quanto ao perfil demográfico, foi possível observar que o sexo feminino deteve os maiores percentuais em todas as variáveis analisadas. Os maiores percentuais de casos confirmados, cura e óbitos ocorreram em indivíduos entre 20 e 29 anos, enquanto que a maior letalidade foi observada entre 50 a 59 anos. Também se verificou que as mulheres gestantes, apesar de representarem uma minoria dos casos notificados, detiveram uma letalidade quase duas vezes maior que as não gestantes. CONCLUSÃO: Logo, a influenza pandêmica afetou significativamente a população brasileira, especialmente em 2009, apresentando padrão de circulação elevado no Sul e Sudeste e maior

\footnotetext{
${ }^{1}$ Graduando em Farmácia pela Universidade Federal de Campina Grande (UFCG), Centro de Educação e Saúde (CES). E-mail: alisonpds2@gmail.com.

${ }^{2}$ Graduando em Ciências Biológicas pela Universidade Federal de Campina Grande (UFCG), Centro de Educação e Saúde (CES). E-mail: diogoleonardosantossilva@yahoo.com.

${ }^{3}$ Doutora em Biotecnologia, Professora Adjunta da Unidade Acadêmica de Saúde da Universidade Federal de Campina Grande (UFCG), Centro de Educação e Saúde (CES). E-mail: brunabdantas@gmail.com.
} 
letalidade no Centro-Oeste. Afetou principalmente mulheres, adultos jovens e foi mais letal entre a faixa etária de 50 e 59 anos, assim como em gestantes.

Palavras chave: Epidemiologia. Vírus da Influenza A Subtipo H1N1. Influenza Humana. Sistemas de Informação em Saúde.

ABSTRACT: OBJECTIVE: To verify epidemiological data on pandemic influenza in Brazil. METHODOLOGY: Documentary and retrospective study, using data from the Department of Informatics of the Unified Health System (DATASUS), between 2009 and 2010. Notifications were collected regarding the final classification and confirmed cases were analyzed by geographic region, evolution, sex, age group, pregnancy condition and lethality rate. RESULTS: During the containment and mitigation phases, there were 97,250 notifications, of which 55.7\% were confirmed and $44.3 \%$ were discarded. The year 2009 concentrated the highest number of notifications $(N=89,642)$ compared to $2010(N=8,664)$. The data by region indicated that the South and Southeast regions had a large number of confirmed cases and deaths, although the Midwest region had the highest lethality in the country. As for the demographic profile, it was possible to observe that females had the highest percentages in all variables analyzed. The highest percentages of confirmed cases, cure and deaths occurred in individuals between 20 and 29 years old, while the highest lethality was observed between 50 and 59 years old. It was also found that pregnant women, despite representing a minority of reported cases, had almost twice as much lethality as non-pregnant women. CONCLUSION: Therefore, pandemic influenza significantly affected the Brazilian population, especially in 2009, with a high circulation pattern in the South and Southeast and greater lethality in the Midwest. It mainly affected women, young adults and was more lethal between the age group of 50 and 59 years, as well as in pregnant women.

Keywords: Epidemiology. Influenza A Virus, H1N1 Subtype. Influenza, Human. HealthInformation Systems. 


\section{INTRODUÇÃO}

A influenza é considerada, em escala global, como questão de preocupação para saúde pública, principalmente, devido à facilidade do agente viral causador em se propagar, podendo assim afetar pessoas em qualquer faixa etária. Esta doença é causada por um vírus classificado, sistematicamente, como sendo da família Orthomyxoviridae. Este vírus causador da influenza pode ser dividido em quatro tipos: $A, B, C$ e D, porém apenas o vírus do tipo $A$ apresentar potencial para causar pandemias, sendo resultante da variação de combinações da hemaglutina e da neuraminidase, além de possuir subtipos, que permitem a infecção do ser humano e de outros animais (ROSSETO; LUNA, 2016; CUGINI et al., 2010; BRASIL, 2020).

Nesse sentido, o vírus H1N1, um subtipo do vírus $A$ da influenza, emergiu como uma ameaça à saúde da população mundial. Tal potencial pode estar também associado a suas propriedades próprias de patogenicidade, como por exemplo, sua replicação se torna mais ampla no tecido epitelial que reveste os brônquios (formado por pneumócitos I e II) em temperatura de $33^{\circ} \mathrm{C}$ em relação a outros subtipos. Geneticamente, o vírus da influenza apesar de sofrer mutações, é considerado como estável, entretanto, não é descartada a possibilidade de se modificar ao ponto de causar um novo surto. Como característica do material genético, o H1N1 é portador de ácido ribonucleico (RNA) de cadeia simples segmentado. Estas características tornam este vírus altamente transmissível, além disso, pode levar ao aparecimento de lesões nos brônquios e nos alvéolos, assim como já foi relatado em estudos. (BELLEI; MELCHIOR, 2011; FRED et al., 2009).

No tocante à sintomatologia, os primeiros sintomas surgem logo após o fim do período de incubação do vírus que, geralmente, dura de um a três dias. A febre, a rinorreia, assim como a dor de garganta, foram os sintomas mais comuns encontrados em pacientes diagnosticados com influenza H1N1 em 2009. Entretanto, os sintomas respiratórios tornam-se mais acentuados à medida que a infecção evolui. Em estudos anteriores já foi relatado o aparecimento de várias síndromes, 
como por exemplo, sintomas respiratórios frustos e a pneumonia viral fulminante, em decorrência da influenza (BELLEl; MELCHIOR, 2011).

Sabe-se que a influenza pode desencadear uma gama de outros sintomas que podem aparecer subitamente, como por exemplo, secreção nasal excessiva, mialgia, mal-estar, calafrios, cefaleia, dor nas juntas e prostração. A fadiga, diarreia, vômito, olhos avermelhados e lacrimejantes, bem como rouquidão, podem ser notados também em alguns casos (BRASIL, 2020).

A maioria dos casos de influenza é tratada quando são sintomáticos. Todavia, os casos de maior risco exigem a necessidade de intervenções específicas, como por exemplo, a terapia antiviral. Os fármacos pertencentes a esta categoria que são utilizados para o tratamento e as medidas profiláticas contra a influenza incluem os inibidores dos canais de íon M2, comoarimantadina e a amantadina, e os inibidores da neuraminidase, como o oseltamivir e o zanamivir(ALMEIDA et al., 2015).

No que se refere à epidemiologia, os primeiros casos de transmissão sustentada entre humanos com o vírus influenza $A(\mathrm{H} 1 \mathrm{~N} 1)$ foram detectados no México e nos Estados Unidos, no final de abril de 2009. A doença espalhou-se rapidamente e, em 11 de julho do referido ano, a Organização Mundial da Saúde declarou a situação de pandemia. Somente no dia 10 de agosto de 2010 foi declarado o fim da pandemia, sendo que dados do dia primeiro de agosto indicavam que haviam casos confirmados laboratorialmente em 214 países, além de um número superior a 18.449 óbitos (WHO, 2011).

Nesse contexto, desenvolver estudos que permitam a compreensão das características de difusão de uma doença pandêmica em território nacional é fundamental para orientação da comunidade civil e científica, assim como para nortear as ações em saúde, fornecendo também uma base para enfrentamento de futuras pandemias, como a que estamos vivendo ocasionada pela propagação do coronavírus (Sars-CoV-2), causador da síndrome respiratória aguda grave (MARQUES et al. 2012; BREHMER et al., 2011; SCHLEMPER JUNIOR; DALL'OGLIO, 2011; HANNA; EVANS; BOOTH, 2020). Dessa forma, o objetivo do presente estudo é descrever características epidemiológicas e demográficas da influenza pandêmica em território brasileiro. 


\section{METODOLOGIA}

\section{Delineamento do estudo}

Trata-se de um estudo documental e retrospectivo, com dados secundários obtidos a partir do Departamento de Informática do Sistema Único de Saúde (DATASUS), considerando os anos de 2009 e 2010.

\section{Local do estudo}

O Brasil é um país localizado na América do Sul, com extensão territorial de 8.510.820,623 km² e é dividido em cinco regiões: Norte, Nordeste, Sudeste, Sul e Centro-Oeste. De acordo com o último censo, a população do país era equivalente a 190.755.799 habitantes, o que confere ao mesmo uma densidade demográfica de 22,4 hab./km², aproximadamente. A maior parte da população correspondia a mulheres (51\%), além de que havia um maior percentual de indivíduos com idade entre 20 e 39 anos (33,5\%) (IBGE, 2020).

\section{Seleção das varáveis e análise dos dados}

A figura 1 mostra como as variáveis foram selecionadas de forma esquematizada. 
Figura 1. Esquematização do processo de seleção das variáveis.

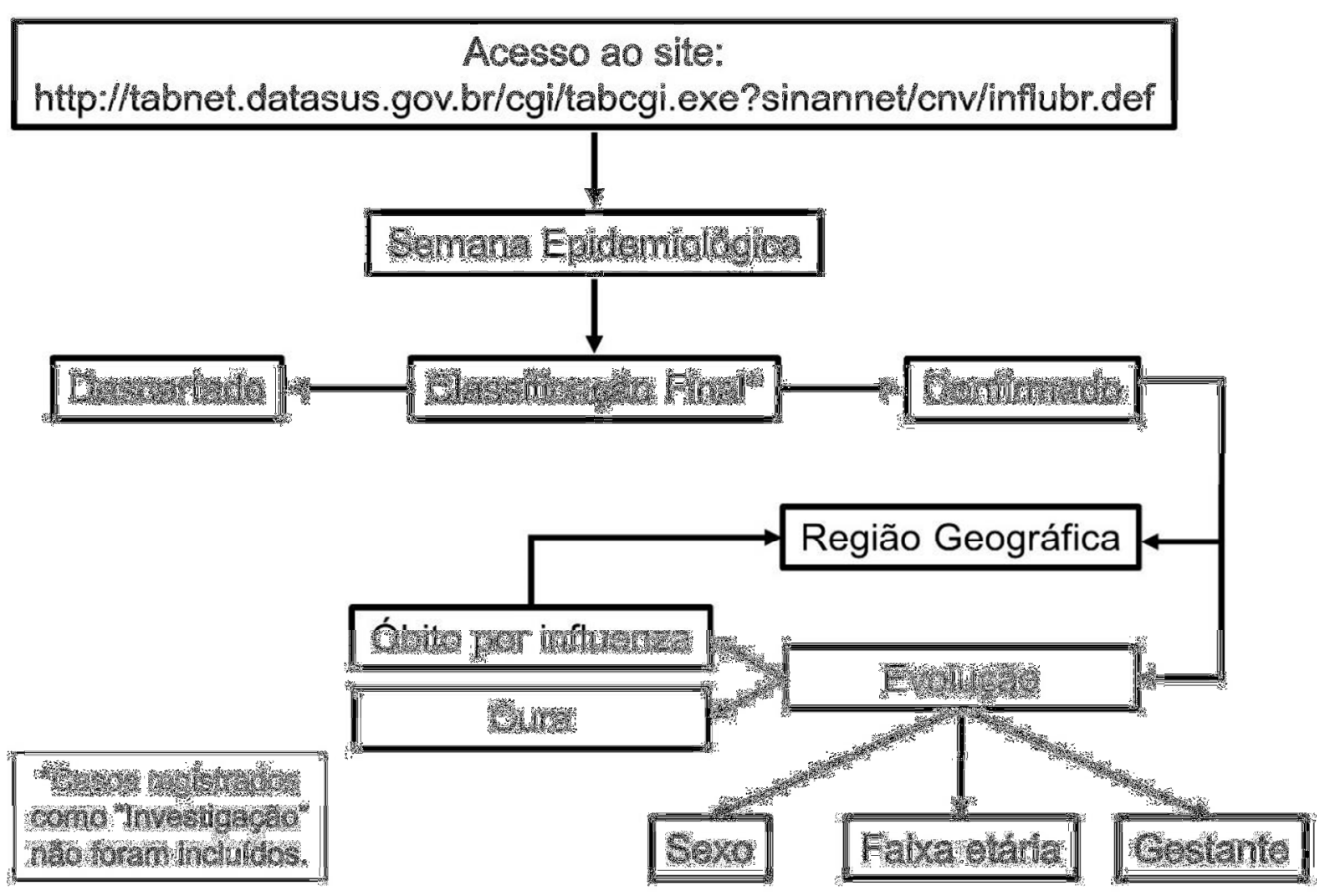

Fonte: Elaborado pelos autores, 2020.

Além disso, foi calculada a taxa de letalidade a partir da seguinte fórmula.

Taxa de Letalidade $=\left(\frac{N^{\circ} \text { total de óbitos por influenza pandêmica }}{N^{\circ} \text { total de casos confirmados por influenza pandêmica }}\right) \times 100$

\section{RESULTADOS E DISCUSSÃO}

Durante a pandemia de influenza, que ocorreu entre 2009 e 2010, a estratégia de enfrentamento adotada pelo Ministério da Saúde foi dividir o período em duas fases: a fase de contenção e a fase de mitigação. A primeira fase correspondeu a um período inicial, entre a décima sexta e a vigésima oitava semana 
epidemiológica (SE) de 2009, em que era possível identificar a origem da infecção, sendo todos casos registrados decorrentes de pessoas que haviam chegado de viagem de países com casos documentados ou de pessoas que tiveram contatocom indivíduos infectados mediante a primeira possibilidade. Já a segunda fase é caracterizada pela transmissão sustentada, ou seja, a transmissão é local, ocorrendo de pessoa para pessoa no país, mesmo sem ter ocorrido viagem internacional por alguma das partes. Esta fase se iniciou na vigésima nona SE de 2009 e durou até o fim da pandemia (PIRES NETO et al., 2013; ROSSETO; LUNA, 2016).

Dito isso, observa-se na figura 01 que em todo o período que corresponde às fases de contenção e mitigação ocorreram 97.250 notificações, com 54.149 casos $(55,7 \%)$ confirmados, enquanto 43.101 casos (44,3\%) foram descartados no Brasil. Além disso, o maior número de notificações aconteceu na fase de mitigação (86.575 notificações), quando comparado a fase de contenção (10.675 notificações), havendo também um maior número de casos confirmados na fase de mitigação (49.781 casos), frente aos casos confirmados durante a fase de contenção (4.368 casos).

Quando analisado por ano, verifica-se que em 2009 ocorreram 89.642 notificações, das quais 53.198 foram confirmados para influenza pandêmica e 36.444 foram descartados. Além disso, o pico de casos confirmados $(N=6.837)$ ocorreu na trigésima primeira semana epidemiológica deste ano. Já em 2010, foram contabilizados 8.664 casos, dentre os quais 973 foram confirmados e 7.691 foram descartados, além de que o maior número de casos confirmados $(\mathrm{N}=99)$ neste ano foi registrado na décima SE. Em todo o período, considerando inclusive a fase pós-pandêmica no ano de 2010, foram confirmados 54.171 casos, enquanto 44.135 foram descartados, perfazendo um total de 98.306 notificações (Figura 1). 
Figura 1. Distribuição dos casos de influenza pandêmica segundo classificação final, por semanaepidemiológica, Brasil, 2009-2010.

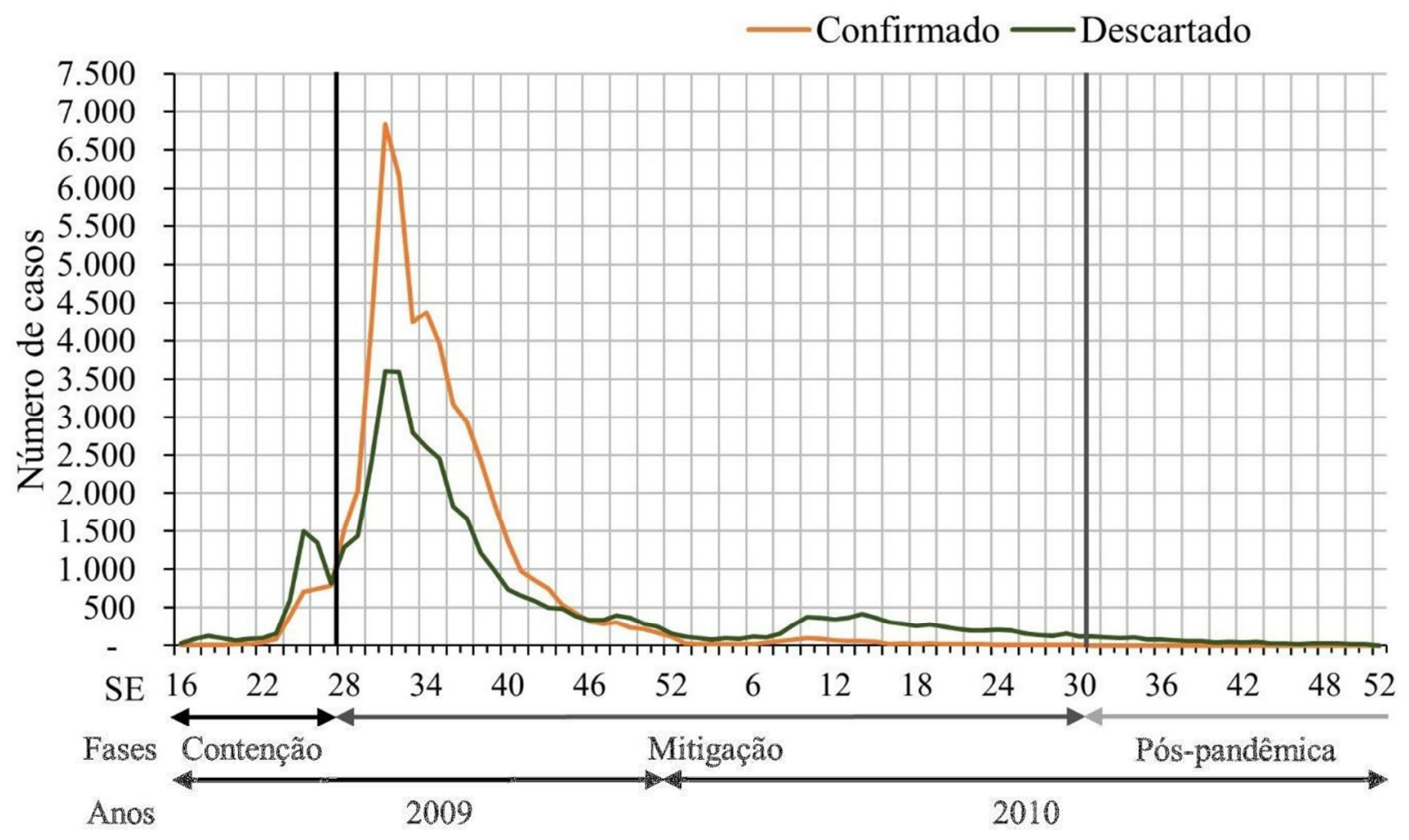

Fonte: Adaptado de DATASUS, 2020.

A grande diferença entre os dados de 2009 e 2010 é decorrente da rápida expansão do vírus no começo da pandemia, associado ao fato de que havia uma carência no fornecimento de informações por parte dos órgãos públicos à população, bem como a inexistência de medicamentos e/ou vacinas que amenizassem o problema (SIMIONI; WOLLMANN, 2015).

Além da quantidade de casos confirmados supracitada, foram contabilizados 2.232 óbitos por influenza e uma letalidade igual a 4,1\% no Brasil, entre 2009 e 2010 (Tabela 1). No México, local onde a pandemia começou, foi registrada uma taxa de letalidade de aproximadamente $1,8 \%$ (CASTILLO-PALENCIA; LAFLAMME; MONÁRREZ-ESPINO, 2012), o que é reflexo da menor proporção de óbitos em relação aos casos, se comparado com o Brasil.

Ao analisar os dados por região, verifica-se que a região Sul deteve a maior parte dos casos confirmados de influenza A $(67,9 \%)$, seguido pelas regiões Sudeste 
$(25,1 \%)$, Centro-Oeste (2,5\%), Norte (2,3\%) e Nordeste (2,2\%). Em relação aos óbitos por influenza, observa-se apenas uma mudança em comparação à distribuição anterior, em que os maiores valores foram registrados no Sudeste $(46,5 \%)$, enquanto que a região Sul $(37,3 \%)$ deteve o segundo maior registro (Tabela 1).

Tabela 1. Casos confirmados, óbitos por influenza e letalidade segundo região de residência, Brasil, 2009-2010.

\begin{tabular}{l|c|c|c|c|c}
\hline \multirow{2}{*}{ Região de residência } & \multicolumn{2}{|l|}{ Casos confirmados } & Óbitos por influenza & \multirow{2}{*}{$\begin{array}{c}\text { Taxa de } \\
\text { Letalidade }\end{array}$} \\
\cline { 2 - 5 } & $\mathbf{N}$ & $\mathbf{\%}$ & $\mathbf{N}$ & $\mathbf{\%}$ & \\
\hline Região Norte & 1.229 & $2,3 \%$ & 100 & $4,5 \%$ & $8,1 \%$ \\
\hline Região Nordeste & 1.176 & $2,2 \%$ & 88 & $3,9 \%$ & $7,5 \%$ \\
\hline Região Sudeste & 13.606 & $25,1 \%$ & 1.038 & $46,5 \%$ & $7,6 \%$ \\
\hline Região Sul & 36.799 & $67,9 \%$ & 833 & $37,3 \%$ & $2,3 \%$ \\
\hline Região Centro-Oeste & 1.361 & $2,5 \%$ & 173 & $7,8 \%$ & $12,7 \%$ \\
\hline Total & $\mathbf{5 4 . 1 7 1}$ & $\mathbf{1 0 0} \%$ & $\mathbf{2 2 3 2}$ & $\mathbf{1 0 0} \%$ & $\mathbf{4 , 1 \%}$ \\
\hline
\end{tabular}

Fonte: Adaptado de DATASUS, 2020.

Diante do predomínio de casos confirmados e óbitos nas regiões Sul e Sudeste, é importante destacar que o elevado número de habitantes e altas densidades populacionais elevam o risco de infecção pelo vírus, facilitando a disseminação de variantes resistentes. Além disso, a atividade do vírus influenza é maior em regiões de transição entre um clima temperado para tropical. Outro fator que pode ter contribuído para isso é a proximidade da região Sul com países onde o vírus influenza circulou mais intensamente (SOUZA et al., 2015; TEIXEIRA et al., 2018).

Aliado a isso, Cerbino Neto, Penna e Werneck (2013) conjecturam que as diferenças regionais na epidemiologia da influenza podem ser decorrentes de uma série de fatores, tais como características da cepa circulante, estrutura etária, prevalência de comorbidades, poluição ambiental, hábitos de vida, e cosazonalidade com outros agentes infecciosos. Em consonância a isso, as diferenças na qualidade de assistência à saúde e na disponibilidade dos recursos podem 
influenciar diretamente nas situações de contraste entre as regiões (FERRER; MARCON;SANTANA, 2008).

Por outro lado, no que se refere a taxa de letalidade também expressa na tabela 1 , o Centro-Oeste $(12,7 \%)$ foi a região que deteve o valor mais alto, vindo em seguida as regiões Norte $(8,1 \%)$, Sudeste $(7,6 \%)$, Nordeste $(7,5 \%)$ e Sul $(2,3 \%)$. De acordo com Azambuja (2010), onovo vírus influenza H1N1 co-circulou no período de inverno no Rio Grande do Sul com vírus sazonais na proporção de 4:1. Isso levanta a hipótese da associação entre a letalidade da influenza e a co-circulação viral. Nesse sentido, é possível que tal fenômeno tenha exercido alguma influência na elevada letalidade do Centro-Oeste, mediante o espalhamento do vírus no decorrer da pandemia.

Na tabela 2, é possível observar as características epidemiológicas de difusão da influenza, frente a características sociodemográficas.

Ao analisar os dados da variável relativa ao sexo, verifica-se para as mulheres, os percentuais de $56,7 \%$ para casos confirmados, 56,9\% para a cura, $57,6 \%$ para os óbitos e $4,1 \%$ para a letalidade. Para os homens, verifica-se os percentuais de $43,3 \%$ para os casos confirmados, $43,1 \%$ para a cura, $42,4 \%$ para óbitos e 4,0\% para a letalidade (Tabela 2).

No que diz respeito à faixa etária, destaca-se o grupo de 20 aos 29 anos, com predominância de casos confirmados $(24,7 \%)$, de cura $(24,9 \%)$, assim como de óbitos $(21,7 \%)$, porém com taxa de letalidade relativamente baixa $(3,6 \%)$ e o grupo com idade igual ou maior que60 anos, com menores números de casos confirmados $(4,9 \%)$ e de cura $(4,8 \%)$, com poucos óbitos $(7,4 \%)$, o que se assemelha ao observado nas menores faixas etárias, porém com uma elevada letalidade $(6,1 \%)$. Entretanto, as maiores taxas de letalidade foram registradas no grupo de 50 aos 59 anos $(8,6 \%)$ e no grupo de 40 a 49 anos $(6,6 \%)$ e a menor letalidade no grupo menorque dois anos $(2,4 \%)$ (Tabela 2$)$.

Percebendo assim, uma predominância da influenza na população feminina, bem como em pessoas com faixa etária entre 20 a 29 anos no Brasil, pode ser explicado devido o fato destes dois grupos serem os mais numerosos de acordo com o perfil demográfico do período em questão, conforme os dados do IBGE (IBGE, 2020). 
Em relação à letalidade, esta apresentou-se maior em pessoas a partir dos 40 anos. Isto pode ser atribuído ao fato de que o sistema imunológico humano sofre alterações funcionais com o decorrer da idade, causando seu enfraquecimento (KINOSHITA, 2014). Além disso, estudos relataram novas evidências de que a redução das funções do sistema imunológico devido o envelhecimento seja, geneticamente, programado, tornando organismo mais suscetível às doenças (ESQUENAZI, 2008). Cabe ressaltar também que o processo de envelhecimento está associado a uma maior prevalência de comorbidades, as quais afetam diretamente a recuperação do indivíduo (ALVIM et al., 2017; CERBINO NETO; PENNA; WERNECK, 2013).

$\mathrm{Na}$ variável referente à gestação, observa-se que houve um menor número de casos confirmados em grávidas $(15,2 \%)$ do que em mulheres não grávidas $(84,8 \%)$. De modo semelhante, nota-se que houve menos curas e óbitos por influenza $(14,1 \%$ e $23,8 \%$, respectivamente) entre mulheres grávidas. É preciso pontuar que ao analisar os dados desta forma não significa propriamente que as gestantes tiveram um desfecho clínico demasiadamente desfavorável ou não, visto que as informações não foram ajustadas a cada grupo. Por outro lado, a taxa de letalidade, a qual permite uma observação mais específica da gravidade da doença, foi superior em gestantes $(6,8 \%)$ quando comparada entre as não gestantes $(3,9 \%)$ (Tabela 2).

Gestantes são mais suscetíveis a infecções, pois para que sejam capazes de sustentar a presença do concepto em seu organismo, ocorrem alterações em seu sistema imunológico. Essas alterações incluem a ativação progressiva do sistema imunológico inato e supressão do sistema imunológico adaptativo (PASTORE; PRATES; GUTIERREZ, 2012), sugerindo que este é o motivo pelo qual a letalidade em gestantes ter sido, consideravelmente, maior que mulheres não grávidas. 
Tabela 2. Frequências absolutas e relativas de casos confirmados e evolução, bem como a letalidade segundo sexo, faixa etária e condição de gravidez, Brasil, 20092010.

\begin{tabular}{|c|c|c|c|c|}
\hline \multirow{2}{*}{ Variáveis } & \multirow{2}{*}{$\begin{array}{c}\text { Casos } \\
\text { confirmados }\end{array}$} & \multicolumn{2}{|c|}{ Evolução } & \multirow{2}{*}{$\begin{array}{c}\text { Taxa de } \\
\text { Letalidade }\end{array}$} \\
\hline & & Cura & Óbito por Influenza & \\
\hline \multicolumn{5}{|l|}{ Sexo } \\
\hline Masculino & $23.431(43,3 \%)$ & $20.646(43,1 \%)$ & $932(42,4 \%)$ & $4,0 \%$ \\
\hline Feminino & $30.740(56,7 \%)$ & $27.233(56,9 \%)$ & $1.264(57,6 \%)$ & $4,1 \%$ \\
\hline Total & $54.171(100 \%)$ & $47.879(100 \%)$ & $2.196(100 \%)$ & $4,1 \%$ \\
\hline \multicolumn{5}{|c|}{ Faixa etária (anos)* } \\
\hline$<2$ & $4.228(7,8 \%)$ & $3.684(7,7 \%)$ & $102(4,6 \%)$ & $2,4 \%$ \\
\hline 2 a 9 & $6.416(11,8 \%)$ & $5.695(11,9 \%)$ & $131(6,0 \%)$ & $2,0 \%$ \\
\hline 10 a 19 & $9.868(18,2 \%)$ & $9.069(18,9 \%)$ & $161(7,3 \%)$ & $1,6 \%$ \\
\hline 20 a 29 & $13.367(24,7 \%)$ & $11.911(24,9 \%)$ & $476(21,7 \%)$ & $3,6 \%$ \\
\hline 30 a 39 & $8.226(15,2 \%)$ & $7.177(15,0 \%)$ & $467(21,3 \%)$ & $5,7 \%$ \\
\hline 40 a 49 & $5.561(10,3 \%)$ & $4.806(10,0 \%)$ & $367(16,7 \%)$ & $6,6 \%$ \\
\hline 50 a 59 & $3.827(7,1 \%)$ & $3.225(6,7 \%)$ & $329(15,0 \%)$ & $8,6 \%$ \\
\hline$\geq 60$ & $2.670(4,9 \%)$ & $2.304(4,8 \%)$ & $163(7,4 \%)$ & $6,1 \%$ \\
\hline Total & $54.163(100 \%)$ & $47.871(100 \%)$ & $2.196(100 \%)$ & $4,1 \%$ \\
\hline \multicolumn{5}{|l|}{ Gestante $^{\star *}$} \\
\hline Sim & $3.342(15,2 \%)$ & $2.788(14,1 \%)$ & $227(23,8 \%)$ & $6,8 \%$ \\
\hline Não & $18.634(84,8 \%)$ & $16.979(85,9 \%)$ & $728(76,2 \%)$ & $3,9 \%$ \\
\hline Total & $21.976(100 \%)$ & $19.767(100 \%)$ & $955(100 \%)$ & $4,3 \%$ \\
\hline
\end{tabular}

*Casos registrados como "Em branco" não foram incluídos.

**Casos registrados como "Ignorado/branco" e "Não se aplica" não foram incluídos.

Fonte: Adaptado de DATASUS, 2020.

A pandemia causada pelo vírus influenza $A(H 1 N 1)$ chegou ao fim em 10 de agosto de 2010. Diante de todo o contexto que envolveu esta emergência de saúde pública, houve uma resposta rápida para o enfrentamento da mesma por parte do SUS, haja vista a adoção de medidas como a ampliação da rede de diagnóstico laboratorial, bem como a aquisição e produção local do antiviral indicado (Oseltamivir). Aliado a isso, houve a mobilização da Rede de Alerta e Resposta às 
Emergências em Saúde (Rede Cievs), fundamental para que o SUS pudesse responder de forma mais adequada ao contexto da pandemia (TEIXEIRA et al., 2018).

Com a disponibilidade da vacina a partir de 2010, foram imunizados, aproximadamente, $46 \%$ da população brasileira na época, o que corresponde a cerca de 90 milhões de pessoas. Tal resultado fez com que o Brasil fosse o país que mais vacinou em todo o mundo. Mediante isso, os bons resultados pela campanha de vacinação em território nacional, foram fundamentais para que as pessoas pudessem voltar gradativamente as atividades diárias (GUERREIRO, 2011; TEIXEIRA et al., 2018).

Os esforços realizados pelo ministério da saúde para combater a pandemia da influenza eram exemplos para serem reproduzidos em pandemias futuras (GUERREIRO, 2011). No atual contexto, em que vivemos uma pandemia causada pelo SARS-CoV-2, uma pergunta fica em aberto: "será que algumas medidas adotadas durante a pandemia por influenza pelo SUS e por outras instituições aliadas poderiam ser eficazes contra a atual pandemia?”.

\section{CONCLUSÃO}

A influenza pandêmica constituiu, portanto, uma doença infectocontagiosa que afetou a população brasileira entre 2009 e 2010. Foi possível observar que a maior parte das notificações ocorreram na fase de mitigação, além de que o ano de 2009 concentrou grande parte das mesmas, de tal forma que o pico da doença ocorreu na trigésima primeira semana do referido ano. Quanto ao perfil da influenza nas regiões brasileiras, verificou-se que as regiões Sul e Sudeste detiveram os percentuais mais altos de casos confirmados e óbitos, embora a maior letalidade tenha ocorridona região Centro-Oeste.

Ademais, os indivíduos mais acometidos pela influenza causada pelo H1N1 foram a população feminina, apresentando leve diferença no número de casos em comparação com a população masculina, pessoas entre 20 a 29 anos, e mulheres 
não gestantes. Por outro lado, a maior letalidade ocorreu entre indivíduos com idade entre 50 a 59 anos e gestantes.

\section{REFERÊNCIAS BIBLIOGRÁFICAS}

ALMEIDA, F. J. et al. Consenso para o tratamento e profilaxia da influenza (Gripe) no Brasil. Sociedade brasileira de pediatria. Disponível em: http://www. sbp. com. br/PDFs/conseso_influenza. pdf. Acesso em: 20 abr. 2020.

ALVIM, M. M. et al. Prevalência e fatores associados ao uso de benzodiazepínicos em idosos da comunidade. Revista Brasileira de Geriatria e Gerontologia, v. 20, n. 4, p. 463-473, 2017.

AZAMBUJA, M. I. A parsimonious hypothesis to the cause of influenza lethality and its variations in 1918-1919 and 2009. Medical hypotheses, v. 74, n. 4, p. 681-684, 2010.

BELLEI, N.; MELCHIOR, T. B.; H1N1: pandemia e perspectiva atual. Jornal Brasileiro de Patologia e Medicina Laboratorial, v. 47, n. 6, p. 611-617, 2011.

BRASIL. Ministério da Saúde. 2020. Gripe (influenza): causas, sintomas, tratamento, diagnóstico e prevenção. Disponível em: https://www.saude.gov.br/saude-de-a-z/gripe. Acesso em: 25 de abr. de 2020.

BREHMER, L. C. F. et al. Revisão integrativa da literatura sobre a Influenza AH1N1. Texto \& Contexto-Enfermagem, v. 20, n. Esp., p. 272-277, 2011.

CASTILLO-PALENCIA, J. P.; LAFLAMME, L.; MONÁRREZ-ESPINO, J. Occurrence of AH1N1 viral infection and clinical features in symptomatic patients who received medical care during the 2009 influenza pandemic in Central Mexico. BMC infectious diseases, v. 12, n. 1, p. $1-9,2012$.

CERBINO NETO, J.; PENNA, G. O.; WERNECK, G. L. Regional differences in mortality associated with pandemic Influenza A H1N1 in Brazil. Cadernos de Saúde Pública, v. 29, n. 1, p. 189-194, 2013.

CUGINI, D. M. et al. Perfil epidemiológico dos casos de influenza A H1N1 em TaubatéSP. BEPA. Boletim Epidemiológico Paulista (Online), v. 7, n. 81, p. 17-25, 2010.

DATASUS. Departamento de Informática do Sistema Único de Saúde. Sistema de Informação de Agravos de Notificação (SINAN). 2020. Disponível em: http://tabnet.datasus.gov.br/cgi/tabcgi.exe?sinannet/cnv/influbr.def. Acesso em: 08 abr. 2020.

ESQUENAZI, D. Imunossenescência: as alterações do sistema imunológico provocadas pelo envelhecimento. Revista Hospital Universitário Pedro Ernesto, v. 7, n. 1, p. 38- 45, 2008.

FERRER, A. L. M.; MARCON, S. S.; SANTANA, R. G. Morbidade hospitalar em idosos antes e após vacinação contra influenza no estado do Paraná. Revista Latino-Americana de Enfermagem, v. 16, n. 5, p. 832-837, 2008.

FRED, J. et al. Vigilância da influenza A (H1N1), novo subtipo viral, no Estado de São Paulo, 2009. BEPA. Boletim Epidemiológico Paulista (Online), v. 6, n. 65, p. 04-15, 2009.

GUERREIRO, S. C. Comunicação de risco: o caso da pandemia H1N1 no Brasil. Universitas: 
Arquitetura e Comunicação Social, v. 8, n. 1, p. 157-172, 2011.

HANNA, T. P.; EVANS, G. A.; BOOTH, C. M. Cancer, COVID-19 and the precautionary principle: prioritizing treatment during a global pandemic. Nature Reviews Clinical Oncology, v. 17 , n. 5 , p. $268-270,2020$.

IBGE. Instituto Brasileiro de Geografia e Estatística. Brasil. 2020. Disponível em: https://cidades.ibge.gov.br/brasil/panorama. Acesso em: 17 abr. 2020.

KINOSHITA, D. Alterações do sistema imunológico relacionadas ao envelhecimento e suas consequências. Revista da Universidade Ibirapuera São Paulo, v. 7, p. 11-19, 2014.

MARQUES, F. R. B. et al. Relação entre morbidade hospitalar e cobertura vacinal contra Influenza A. Acta Paulista de Enfermagem, v. 25, n. 5, p. 686-693, 2012.

ROSSETTO, E. V.; LUNA, E. J. A. Relacionamento entre bases de dados para vigilância da pandemia de influenza A (H1N1) pdm09, Brasil, 2009-2010. Cadernos de Saúde Pública, v. 32,n. 7, p. e00014115, 2016.

PASTORE, A. P. W.; PRATES, C.; GUTIERREZ, L. L. P. Implicações da influenza A/H1N1 no período gestacional. Scientia Medica, v. 22, n. 1, p. 53-58, 2012.

PIRES NETO, R. J. et al. Pandemic influenza A (H1N1) 2009: epidemiological analysis of cases in a tropical/semi-arid region of Brazil. Revista da Sociedade Brasileira de Medicina Tropical, v. 46, n. 2, p. 141-146, 2013.

ROMERO-MÁRQUEZ, R. S.; ROMERO-ZEPEDA, H. Perfil epidemiológico de la influenza A H1N1 en Querétaro. Revista Médica del Instituto Mexicano del Seguro Social, v. 48, n. 4, p. 377-382, 2010.

SCHLEMPER JUNIOR, B. R.; DALL'OGLIO, A. C. A pandemia de influenza espanhola (1918) em Florianópolis, Santa Catarina, Brasil. Arquivos Catarinenses de Medicina, v. 40, n. 3, p. 104-114, 2011.

SIMIONI, J. P. D.; WOLLMANN, C. A. Mapeamento da gripe A (influenza A-H1N1) no estadodo Rio Grande do Sul no período de janeiro a outubro de 2012: casos confirmados, óbitos e curas. Boletim de Geografia, v. 33, n. 1, p. 123-132, 2015.

SOUZA, T. M. L. et al. Oseltamivir-resistant influenza A(H1N1)pdm2009 strains found in Brazil are endowed with permissive mutations, which compensate the loss of fitness imposed by antiviral resistance. Memórias do Instituto Oswaldo Cruz, v. 110, n. 1, p. 101-105, 2015.

TEIXEIRA, M. G. et al. Conquistas do SUS no enfrentamento das doenças transmissíveis. Ciência \& Saúde Coletiva, v. 23, n. 6, p. 1819-1828, 2018.

WHO - World Health Organization. Pandemic Influenza A (H1N1). Geneva: WHO, 2011. 72 p. Disponivel em: https://www.who.int/csr/resources/publications/swineflu/h1n1_donor_032011.pdf. Acesso em: 28 abr. 2020. 